\title{
LA DRAMATURGIA DE RÓMULO GALLEGOS
}

\author{
Luis CHESNEY-LAWRENCE \\ Universidad Central de Venezuela \\ lchesney@cantv.net
}

Resumen: Durante la primera década del siglo xx el teatro venezolano comenzó una serie de innovaciones, apartándose del costumbrismo imperante, al tiempo que en el contexto socioeconómico se imponía un sistema de gobierno autoritario. En este ambiente surge el grupo La Alborada, que reunió a un grupo de dramaturgos notables, uno de los cuales era Rómulo Gallegos, quien con sus obras abrió en aquella época la escena hacia un drama más moderno, ampliando el hasta entonces estrecho panorama teatral. El rememorar su obra dramática, actualizando nuevos hallazgos, amplía el conocimiento y entendimiento de su obra.

Abstract: During the first decade of the Xx century the Venezuelan theater began a series of innovations, going far away from the prevailing local «costumbrismo», at the time that in the socioeconomic context was imposed a system of authoritarian government. In this ambiance arises the group La Alborada, all of them remarkable dramatists, one of which was Rómulo Galllegos, who with his works opened the scene towards a more modern drama, expanding the narrow theatrical panorama. Recalling his 
plays, and updating new findings, extends the knowledge and understanding of its work.

Palabras clave: Teatro. Costumbrismo. Historia. Venezuela.

Key Words: Theatre. «Costumbrismo». History. Venezuela.

\section{INTRODUCCIÓN}

Rómulo Gallegos (1884-1969) es uno de los autores dramáticos venezolanos más interesantes y al que poco se le reconoce. Su éxito como novelista ha tenido que ver en esto, opacando su teatro, aunque no debe olvidarse que sus comienzos lo fueron como dramaturgo y que sus obras teatrales, también muy poco conocidas, tienen significación y proyección en el teatro venezolano como ahora se intenta postular aquí, en términos generales y dentro de los límites de un artículo.

Lo primero que llama la atención en su trayectoria dramática es la existencia de cierta imprecisión en el recuento de su obra teatral. En este sentido, y de acuerdo a fuentes recogidas en esta investigación, la mayor parte de sus obras dramáticas y otras que tienen relación con éstas, fueron escritas en dos partes: la primera, en un breve período de la segunda década del siglo Xx y la segunda, en los años cuarenta del mismo siglo.

Estos dos períodos se encuentran insertos en marcos contextuales bien diferentes: el primero en torno a las corrientes modernas que entraban en Venezuela, y el segundo a los cambios que comienza a experimentar el país tras la desaparición de la dictadura de Gómez, ambos de profundas reflexiones en Gallegos y que quedarán expresadas en toda su obra, tanto dramática como novelística. En este artículo se aborda especialmente el primer contexto, el modernista, por cuanto representa su ambiente inicial, el de sus mayores aspiraciones iniciales y en el que comienza a aparecer su teatro antes que nada. Toda la investigación es de carácter documental, algunos documentos y obras provienen de originales, dándose preferencia a las fuentes primarias. Al cumplirse cien años de su natalicio, el recordar su obra dramática, actualizando nuevos hallazgos, es un homenaje que se le rinde al autor. 


\section{EL MARCO DEL MODERNISMO EN EL TEATRO}

Ha existido la idea en la mayor parte de los estudios sobre el teatro de comienzos del siglo XX de que el sainete criollo no sólo ocupó gran parte de la primera mitad del siglo XX, sino que, además, este género era prácticamente el único de la época, acreditado claro está por el amplio número de sus piezas y autores, así como también por exteriorizarse como un género auténticamente venezolano e inspirado en la propia realidad; aspectos no difíciles de alcanzar por cuanto el ambiente cultural oficialista de aquellos años propugnaba también manifestaciones nacionalistas de este tipo, todo lo cual fue en desmedro de otras manifestaciones que con esfuerzo emergían al mismo tiempo.

Según esta forma de pensar, quedaría implícito, igualmente, algo que no podría desconocerse en la escena nacional de la época, cual era que se comete un prejuicio al reconocer como el personaje auténticamente venezolano sólo al hombre del pueblo que muestra el sainete, y no al burgués o pequeño burgués que ya comienza a habitar la ciudad y a tener figuración intelectual. Así, el personaje popular queda congelado y estigmatizado como el de los barrios pobres de la ciudad o el del campesino analfabeto, porque la mayor parte de la población vivía en ámbito rural y era iletrada.

Sin embargo, esto no fue así. El sainete no fue ni el único género dramático que representó a la literatura nacional de esa época como aquel pobre no fue el personaje popular que existió, ni tampoco este hecho obliga a dejar en un lugar secundario la preocupación estética que tuvieron muchos otros dramaturgos cuyas propuestas se alejaron del sainete, como lo fue el grupo de autores de La Alborada, del que devendrá Gallegos.

En este artículo sólo se dará una visión panorámica y esquemática del movimiento llamado Modernismo y sus representantes dramáticos, así como del efecto cultural que tuvieron las llamadas vanguardias en el teatro, para lo cual se efectúa una revisión de los autores que transitaron estas modalidades que anuncian notables cambios que experimentaría el drama. Además, se incluye a un grupo de dramaturgos que pensaron en expresar con sus obras el alma nacional, no tan clara entonces, siendo esto precisamente uno de los postulados de los dramaturgos del grupo La Alborada (1909) y La Proclama (1910), cuya visión, aunque un tanto pesimista, muestra reflexiones estéticas interesantes en sus propuestas dramáticas. Según ellos, el modelo a seguir se orientaría por una inspiración democrática y burguesa, con la cual se vencería a la barbarie y se establecería una verdadera conciencia nacional, lo cual da una clara visión aperturista al movimiento teatral de la época. 
Para poder entender mejor estos dos conceptos tan importantes en el desarrollo de la literatura venezolana y latinoamericana, habría que explicar primero que hablar de lo moderno se refiere a algo distinto a lo que fue anterior, a lo no moderno, a lo antiguo, y esto en el ámbito latinoamericano se conectó con procesos culturales aparecidos en Europa, como fueron la Revolución Industrial, cuya plenitud estructural se manifestará en el siglo XIX, pero que en América Latina, que ya tenía nexos con este período desde fines y del siglo XVIII, este concepto no se articulará sino hasta fines del siglo XIX, en lo que se ha dado en llamar «civilización industrial» (Osorio, 1988). Por estas razones, el período que va desde 1880 a 1910, aproximadamente, es el que se conoce como el de la modernización, durante la cual el continente entraría a formar parte del «mundo moderno».

En este marco surge y se desarrolla el movimiento literario denominado Modernismo. En su propuesta estética se destaca la idea de superar los patrones literarios del pasado y reemplazarlos por nuevos valores, tomados en parte de autores como Goncourt, Zola y Tolstoy, junto a su gran exponente latinoamericano, Rubén Darío, entre otros, quienes, al manifestar una conciencia del desajuste y desencanto del mundo, proponen que la belleza y el arte universal sean las fórmulas de su defensa. Estos autores fueron traducidos y publicados en los periódicos oficiales del guzmanismo y en dos revistas cimeras del modernismo en Venezuela, como fueron El Cojo ilustrado y Cosmópolis, incorporándose luego, de especial interés para el teatro, $\mathrm{La} \mathrm{Al}$ borada, La Proclama y Fantoches, todas ellas prácticamente ignoradas por el mundo crítico del teatro venezolano.

Dado que en Venezuela se mantuvieron vigentes las mismas condiciones socioculturales más allá de este período mencionado, la producción literaria del segundo decenio del siglo XX también se mantendrá dentro de la misma poética modernista (conocida también como postmodernista, mundonovista o etapa crepuscular), reuniendo a un mayor grupos de escritores y dramaturgos relevantes dentro de ella. En esta nueva periodización, ampliada, se encuentran dramaturgos —además de novelistas - como Salustio González Rincones, Leopoldo Ayala Michelena, Ángel Fuenmayor y Rómulo Gallegos, junto a autores continentales como Antonio Acevedo Hernández (Chile) y Armando Discépolo (Argentina), entre otros. Muchos de ellos, en su producción posterior, se alejarían del Modernismo, ajustándose a las nuevas propuestas que incorporará el movimiento siguiente, el de las Vanguardias de los años veinte.

En resumen, en esta época modernista continental, de crisis, reajustes y cambios, sociopolíticos y estéticos, se encuentran imbricados tanto los au- 
tores canónicos de Modernismo, como Darío, Lugones, Nervo, los ya mencionados dramaturgos crepusculares, González, Ayala, Fuenmayor y Gallegos, y los más recientes como Huidobro de Chile (Osorio, 1988: xvii-xix).

Dado su origen general y universal, su alcance también fue muy amplio y esto explica que surgieran manifiestos, proclamas y contramanifiestos tanto en Europa como en Latinoamérica, simultáneos la mayoría de las veces, y todos de corte vanguardista. La Vanguardia cuestionó básicamente que se le atribuyera su origen a las escuelas europeas, considerando que ellos surgieron de impulsos propios, de procesos culturales locales (como la crítica al Modernismo y su reflexión frente a su realidad, especialmente política), los que luego se expandieron por Latinoamérica hasta relacionarse con el campo internacional; otra crítica que recibió fue su marcada visión continental, regional, lo que junto al deseo de distanciarse de los «ismos» europeos, los llevaría a utilizar expresiones diferentes de aquellos, como «arte nuevo»o «nueva sensibilidad»; y, finalmente, propusieron la superación ideológico-literaria de la deformación que producía el análisis de sus obras según géneros, dentro de lo cual ahora podría ser entendido con más claridad, por ejemplo, el sentido de la obra dramática E' utreja (1927) del entonces vanguardista Arturo Úslar Pietri (Osorio, 1988: xvii-xxxv).

El período hasta donde se registra este movimiento de la Vanguardia culminará en 1929. Es decir, su duración ha quedado circunscrita a dos importantes fechas históricas, que van desde la Primera Guerra Mundial hasta la crisis económica internacional de 1929, período éste que se caracterizó por la expansión del sistema económico capitalista, por el desarrollo de las burguesías urbanas, de sus capas medias, por la aparición de fuertes sectores de trabajadores organizados, y por el prosperar político de movimientos de corte popular. En lo cultural, se constata como gran acontecimiento el movimiento de la Reforma universitaria de Córdoba (Argentina), en 1918, que luego se expandió a otros países durante los años veinte (en Venezuela, la Universidad Central de Venezuela permanecía cerrada entre 1912 y1922). A su vez, 1929 marcó el fin de la hegemonía estética del Modernismo, lo cual no significó el término de su producción literaria, que siguió hasta casi mitad del siglo.

Entre los actores institucionales del Modernismo en Venezuela se debe destacar El Cojo Ilustrado (1892-1915), revista que según Domingo Miliani (1985) fue la síntesis de tres generaciones, heredera de una larga tradición de revistas literarias del siglo XIX. Mirla Alcibíades (1989) reconoce que, gracias a la acertada dirección de su propietario, José María Herrera Irigoyen, pudo 
mantener una calidad y actualidad, sustentada en un lector exclusivo (por el cobro de un precio relativamente alto por la revista), y en el pago de las rigurosamente seleccionadas colaboraciones. Esto, aparentemente, fue el secreto de su larga duración, aunque ello atentara contra un proyecto editorial de corte estrictamente cultural. En términos del Modernismo se consideró a esta revista como el «enlace entre la cultura venezolana y la universal» $(\mathrm{Ca}-$ rrera, 2001: 108). De esta revista y de Cosmópolis, surgiría la primera generación de autores modernistas, entre los que se encuentran, entre otros, los siguientes dramaturgos: Pedro Emilio Coll, Manuel Díaz Rodríguez y Pedro César Dominici.

La relevancia que puede tener esta revista para el teatro venezolano deviene de la expresión «teatro modernista» que presentara Alba Lía Barrios (1997: 60) para denominar a aquellas obras que fueron publicadas por esta revista y que se emparentarían estéticamente con el Modernismo, lo cual no sólo creaba un nuevo espacio para el teatro, sino que podría explicar en mejor forma muchas de estas propuestas surgidas especialmente durante la primera década del siglo $\mathrm{XX}$.

De cualquier forma, esta revista publicó a muchos dramaturgos de su época, entre los cuales pueden mencionarse, entre 1908 y 1915, a los siguientes: Eduardo Innes (1908), Simón Barceló y Pedro E. Coll (1909), Salustio González, Julio Planchart, Enrique Soublette y Francisco Yánez (1910), Julio Rosales (1910 y 1912), Rafael Benavides (1911 y 1912), Luis Churión (1912), Juan Santaella (1913) y Juan Duzán (1913 y 1915).

Otra de las revistas de esta misma corriente fue Cosmópolis (1894-95), la que, según la autorizada opinión de Pedro Grases (1944 y 2001), conformaron un equipo de intelectuales que sintieron el incentivo de realizar algo compartido en torno a la cultura venezolana con mayor convencimiento que en $E l$ Cojo Ilustrado, al punto que «podría decirse que Cosmópolis singulariza y precisa una generación literaria» (Grases, 1944: 12). Así, en 1894, un grupo de los más jóvenes literatos venezolanos, también colaboradores de El Cojo, quisieron independizarse y fundar su propia revista. Ésta fue Cosmópolis, a la que subtitularon, muy significativamente, «Revista Universal», lo que en el contexto cultural de ese entonces fue realmente como un grito literario revolucionario, lo cual en algunos timoratos creó indignación y, en otros más indiferentes, provocó las acostumbradas sonrisas que suelen darse a este tipo de propuestas. Para despecho de todos ellos, y a pesar de su corta duración, la revista hizo historia en Venezuela y en el resto del continente, incluyendo su manifiesta naturaleza dramática con la que surge. 
Sus Directores y Redactores iniciales fueron Pedro César Dominici, Pedro Emilio Coll y Luis Manuel Urbaneja, los dos primeros también dramaturgos. En el n. ${ }^{\circ} 9$ de la revista (octubre de 1894) se retira Coll. Reaparece la revista en Mayo de 1895 con el n. ${ }^{\circ}$ 10, teniendo como único Director a Coll, y como Redactores a Andrés A. Mata y Luis Manuel Urbaneja, figurando además como Redactor-corresponsal (en París) Pedro César Dominici. Su última entrega fue el n. ${ }^{\circ} 12$, fechado en junio de 1895. Los objetivos de la revista, de nombre stendhaliano, incluían además del «tomar contacto con literaturas extranjeras que creíamos necesario para nuestra educación estética y social, el intenso deseo de revivir o despertar la observación inmediata y contemporánea de nuestro contorno nacional» (Grases, 1944: 16). Entre sus colaboradores venezolanos, dramaturgos, figuraron Polita J. de Lima, Rafael Bolívar Coronado, Nicanor Bolet Peraza, Manuel Díaz Rodríguez y Luis Churión; y entre los extranjeros se publicaron artículos de dramaturgos como Emil Zola, Víctor Hugo y Emilia Pardo Bazán, además de los de Rubén Darío, Charles Baudelaire, León Tolstoy, Paul Bourget, León Claudel e Hipólito Taine.

El primer artículo del primer número de la revista, titulado «Charloteo», escrito por el equipo completo de sus directivos, tiene una forma dialogada, de influencia teatral, posiblemente por las inclinaciones de sus redactores (Coll, Dominici y Urbaneja), quienes presentan sus ideas, las que remiten sin equívocos a sus principios y a su contenido dramatúrgico moderno, como lo puntualiza la edición de Cosmópolis (de 1 de mayo de 1984: 21-25), cuyo diálogo reza así: Coll: «queridos cofrades, estamos solos, nadie nos oye y podemos hablar con franqueza...»; Dominici : «Yo creo que debemos recordar el medio ambiente en que vivimos: aquí está atrofiado el espíritu por la indiferencia, pueden contarse las personas que leen un drama de Ibsen o una estrofa de Paul Verlaine...».

\section{LA ALBORADA (1909) Y LA PROCLAMA (1910)}

La Alborada también fue una revista semanal de escasa vida, aunque suficiente para dejar un buen recuerdo en la literatura y de un gran valor para el teatro, que aún no ha sido suficientemente estudiada ni reconocida. Inicialmente, cinco jóvenes, contagiados por el fervor literario, dieron el paso para constituirse en voceros de una nueva actitud frente a la literatura venezolana. Éstos fueron: Henrique Soublette (que la financiaba), Julio Planchart, Julio H. Rosales (el único conocido entre ellos por haber ya escrito cuentos 
en El Cojo en 1906), Salustio González Rincones y Rómulo Gallegos (Planchart, 1972: 422 y Medina, 1963). Su lema fue «sustituir la noche por la aurora».

Su inicio coincidió con la caída del gobierno de Castro, lo cual para sus integrantes «presagiaba una nueva era de libertad y democracia para el país» (Medina, 1963: X), razón por la cual estos jóvenes lo celebraron casi como un hecho histórico. Mas, como lo reconoce uno de los alborados, Julio Rosales, «el posterior afianzamiento de la trágica dictadura gomecista hizo de aquella generación un grupo de hombres en perenne protesta intelectual» (Medina, 1963: X). Esta actitud derivó con el tiempo, especialmente en Gallegos, hacia el esbozo de un fuerte y sostenido planteamiento sobre la transformación social y política del país. Por esta razón, a este grupo se le considera realmente como un movimiento de opinión no solamente de carácter intelectual o literario, sino también político y humano muy significativo en la cultura venezolana.

En este sentido el alma de La Alborada estaba formada por el dicho repetido «el dolor de patria», visto a la luz del «estado de atraso de Venezuela, su pobreza y su ignorancia [que] nos llenaba de congoja el corazón» (Planchart, 1972: 423), y eso era lo que querían expresar en la revista. Su importancia radica en haber constituido un «núcleo de fecundos pronunciamientos literarios» y en que estos cinco nombres cultivaron el drama con relativo éxito.

De esta forma, se podría decir que la concentración de la ideología de $L a$ Alborada se dio en algunos cuentos y declaraciones sobre teatro de Soublette, en las primeras obras dramáticas de Gallegos, ciertamente en el drama de Planchart La República de Caín, y también en los de Salustio González o los de Rosales, todo lo cual constituirá un tema de la mayor significación, que amerita una sección especial destinada a estudiar esta dramaturgia, que se presenta más adelante.

La Proclama surgió el 29 de junio de 1910, cuando circuló el primer y único número de esta revista. En su contenido figuraban artículos de Rómulo Gallegos, Julio Planchart y Henrique Soublette. Este último escribió el editorial en donde ardía la llama de la «revolución de las ideas», porque La Proclama se presentaba como un semanario de combate: «venimos a lanzaros una serie de proclamas de guerra». Combatía el lirismo «de las dormidas lagunas, los cisnes fantásticos, los claros de luna, las visiones funestas, las vírgenes pálidas y las formas gráciles», impulsando el «aliento futurista» (en el mismo año en que Marinetti publicaba su Manifiesto Futurista). El texto de 
este editorial trae muy significativas claves para entender las obras de estos dramaturgos:

No, yo quiero cantar los esfuerzos humanos

Coronados de éxito, fúlgidos de heroísmo:

¡Las conquistas que dotan al hierro de pies y manos!

Las máquinas rápidas y trituradoras

$Y$ los automóviles fugaces y ufanos,

Los acorazados, las locomotoras

¡Y el milagro supremo: los vuelos de los aeroplanos!

(La Proclama, 1998: 442).

Durante los primeros tres meses del año 1909 se editó en Caracas la revista La Alborada, que en sólo ocho números formó lo que se ha denominado una «conciencia» de generación de gran importancia en la literatura y el teatro venezolanos. Unidos por su preocupación por la situación sociopolítica del país, el «dolor de la patria», sus integrantes tenían en esa fecha más o menos la misma edad: Rómulo Gallegos, 25 años; Julio Planchart y Julio Rosales, 24 años; Salustio González, el último en incorporarse, y Henrique Soublette, 23 años. Este último, falleció prematuramente en Caracas, en 1912, por lo que no tuvo la oportunidad del futuro para dejar mayores testimonios y reflexiones sobre esta revista.

Son numerosos los estudios que se han dedicado a desentrañar y analizar el alcance de esta obra en el campo literario, pero muy pocos los que han ahondado en los aspectos de su dramaturgia, como se propone en esta investigación. Testigos de excepción del fin del régimen de Cipriano Castro, en diciembre de 1890, se sintieron llamados a intervenir en el destino de Venezuela para instaurar la libertad y la democracia. Esta alegría inicial poco duró. El gobierno que siguió afianzó la trágica dictadura gomecista e hizo que su voz fuera una oportuna y constante protesta intelectual.

El grupo comenzó por ser una simple reunión de estudiantes de la Universidad, en donde ensayaban sus primeras experiencias como escritores, «repitiendo los esquemas de todas las generaciones literarias de nuestro país: rebeldía, franqueza a veces rudas, sinceridad en los postulados, revisión de valores, ansia de afirmarse en el escenario de la creación literaria, búsqueda de nuevos horizontes, coraje en la pasión y decisión en el sacrificio que el cultivo de las letras impone» (Medina, 1963).

En este sentido, como ha señalado Rosales, los «alborados» caminaron siempre juntos, solidariamente unidos, con la esperanza en un mañana inde- 
pendiente. Bastaría leer el editorial de su primer número, titulado «Nuestra intención», para conocer sus ideas, en donde aparecen frases como «salimos de la oscuridad», «la presión de aquella negra atmósfera», «nuestro oscuro pasado», «nuestro silencio nos da derecho a levantar la voz», «al ver apuntar en su horizonte la alborada de la esperanza», «en la hora del despertar». En su número tercero, se incluye su lema: «sustituir la noche por la aurora».

Hasta ese entonces el canon literario lo aportaba la revista El Cojo Ilustrado, en contra del cual apuntan en primer término los alborados, aunque en definitiva todos terminaron colaborando con esta revista. Resaltan, en sus ocho números aparecidos de la revista, sus símbolos (comenzando por el título y por su lema) y el contenido de sus artículos dedicados a los ciudadanos con un hálito esperanzador, para que la aurora de 1909 no fuera defraudada. Así lo han interpretado, igualmente, la mayor parte de sus estudiosos.

En sus ocho entregas (128 páginas) se publicaron pocas referencias al teatro, pero éstas son lo suficiente como para dar un marco de su pensamiento que pronto se complementaría con obras dramáticas de todos ellos. En lo concreto, se publicó la obra Homúnculos, de Pedro E. Coll, el cuarto acto de la obra Brand, de Henrik Ibsen, relatos de Santiago Rusiñol, y cuatro notas sobre el teatro nacional, una en la que se califica a éste como «página de desastres ... hay que hacerlo desde el principio, porque no hay nada, nada, nada, hecho en esta materia» (28-02-1909: s. p.), y otra en la cual se critica la obra Cuento de Navidad (1909), de Simón Barceló, expresando que «nuestro público no es difícil de contentar, tiene un gusto artístico grosero. Le basta a un autor, para el éxito, adular el sentimiento al espectador. Pasiones primitivas y violentas, ideas de honor, de valor, de dolor, en su más alto grado de romanticismo...» (21-03-1909: s. p.).

En 1910, Soublette anunciaba la reaparición de La Alborada, comunicando nuevas ideas y destacando los grandes problemas del país: «incultura e ignorancia fuentes de todos los demás. Pauperismo - Abandono. Lujuria, Juego, Alcoholismo. Tuberculosis, Sífilis, Mortandad infantil. Y los remedios infalibles son: Cultura, Instrucción, bases del régimen salvador. Entusiasmo, Iniciativa. Economía. Moralidad, Temperancia. Higiene» (pp. 184-185). No existen más noticias sobre esta nueva aparición, excepto este anuncio.

La Alborada fue, sin duda, un proyecto audaz e idealista de un grupo de jóvenes que pretendieron constituirse en un relevo generacional, en el espacio literario moderno, y desde ahora muy especialmente en el teatral. En su quehacer artístico queda la huella de un positivismo imperante que se adhe- 
ría al realismo y al naturalismo y que, por lo demás, brillaría hasta fines de la primera mitad de la década del diez, todo lo cual despertó el interés por las grandes corrientes del pensamiento universal. Es en este período, precisamente, que surge el interés del grupo por el teatro, como bien expresa Jesús Sanoja (1998) al comentar este aspecto, señalando que este período estuvo «contaminado o purificado por una pasión teatral tan real y dinámica que superó a la que por la poesía alimentaba Salustio y por la narrativa Gallegos» (p.10). El fin de La Alborada fue preparado por orden del propio dictador Gómez, quien no estaba dispuesto a tolerar este tipo de publicaciones, como lo relata el alborado Julio Planchart:

El gobierno de Gómez no veía ya con buenos ojos la libertad de prensa y necesitaba un diario continuador de la labor de «El Constitucional» de Gumersindo Rivas, del tiempo de Castro; ya estaban hechos los arreglos para fundarlo y en breve apareciera. Entonces el Gobernador citó a los periodistas, los reunió y los increpó y les dijo cuáles eran las normas a que debían sujetarse en sus publicaciones y hasta uno de ellos, Leoncio Martínez, fue enviado a la cárcel. A la reunión provocada por el Gobernador asistimos Henrique Soublette y el que esto escribe, y al salir de la reunión ambos nos dijimos: «La Alborada» (Planchart, 1944: 23, nota 17).

\section{LA DRAMATURGIA DE RÓMULO GALLEGOS}

A partir de las fuentes bibliográficas disponibles, así como de su correspondencia con sus compañeros y amigos de La Alborada, se puede inferir que en 1910 Gallegos ya comentaba algo sobre su obra Los ídolos y otras que se mencionarán más delante. En carta a Salustio González, fechada el 19 de noviembre de 1910, quien se encuentra ya en Barcelona (España), le comenta sobre esta obra: "Y empezar por... por: "Les Ydoles" - ya no me atrevo ni a nombrarlos en Castellano-- Será la yo no sé Quartésima edición de los susodichos y que, así que la termine te mandaré para que tú veas si allá puede dar resultados, luego continuaré «Las novias muertas», hoy estancadas, i si la cosa va dando como tú crees, seguirá lo demás; «Manía», «Entre las ruinas». Ya ves, títulos tengo» (Sanoja, 1998: 357).

La pista sobre esta obra continúa en su correspondencia a este amigo el 3 de enero de 1911, en donde le comenta sobre las observaciones que hiciera el autor catalán Rusiñol a sus obras: «esto hice con «Los ídolos», que por todo suma 80 páginas para 4 actos i no tiene parlamentos largos. Pronto te lo mandaré, está escrito en máquina» (Sanoja, 1998: 370). El 22 de febrero de 
ese mismo año le pregunta: «¿qué te ha parecido "Los ídolos?"》(Sanoja, 1998: 363). Igual ocurrirá el 4 de noviembre cuando le vuelve a consultar: «¿qué hay de "Los ídolos"? ¿Ni siquiera editor por cuenta y riesgo suyo?» (Ibid.: 370). Finalmente, el 5 de septiembre de 1912, le solicita la devolución del texto: «inclúyeme también 'Los ídolos' que reformaré también, aunque no todavía» (Sanoja, 1998: 377).

Sobre esta misma obra el investigador Javier Lasarte ha expresado, en entrevista efectuada para la televisión por José Antonio Rial, en 1994, que esta pieza y Los predestinados serían versiones de una misma obra, esta última escrita probablemente antes, en 1908, y publicada parcialmente en 1964. Esta obra aparece publicada completa en 1984 y no ha sido estrenada aún. El manuscrito, que esta investigación recuperó de Los ídolos, efectivamente cumple con todas estas indicaciones: consta de cuatro actos, tiene una extensión de 79 páginas y tampoco ha sido llevado a escena.

De las obras que Gallegos menciona en esta correspondencia reseñada, nada se sabe de Manía, de hecho esta sería la primera vez que se menciona. No ocurre lo mismo con la pieza Entre las ruinas, que se encuentra bien documentada en la correspondencia de Gallegos. En efecto, en carta, fechada el 3 de enero de 1991, éste le solicita a González que le recopile información para esta obra: «estos datos son: un sugeto de 12 años fuese a esa a educarse, allí pasó 13 años i regresó. Naturalmente, trece años son suficientes para imprimirle a un mozo la fisonomía de un medio energético como ese (esto parece un editorial de La Alborada) i ya está dicho todo. Necesito documentar el lenguaje del tipo i además algo panorámico de esa ciudad, porque el sugeto en cuestión es tío que se las lió cuando la semana sangrienta: sucesos, lugares donde pasaron, en fin, tú no eres bruto» (Sanoja, 1998: 360).

Finalmente, en correspondencia de febrero de 1911, decide dejar esta obra expresando: «respecto al tipo de "Entre las ruinas", también lo aplazo; en primer lugar esto no sé todavía si lo haga drama o novela creo que es mejor lo último, por extenso e intenso el asunto» (Sanoja, 1998: 363). Esta idea culminó en un cuento, publicado en 1911.

La siguiente pieza que se menciona es El motor. Fechada en junio de 1910, el plan de esta obra también viene reseñado en su correspondencia. Con fecha de 3 de enero de 1911, se sabe que Gallegos pidió a González la opinión de Rusiñol, sobre lo cual expresó: «lo que me dices de Rusiñol i "El motor" no es propiamente para alegrar i eso que no sé todavía como me ha- 
brá dejado la opinión, que no es un juicio, de Don Santiago. Pero lo de las treinta cuartillas por acto i que estoy mui dispuesto a hacer con el 'Motor' lo que tú con 'Naturaleza Muerta' i creo que me convendría mucho, de manera que si Rusiñol me desahucia i no puedes hacer nada con el referido se moviente, avísame para proceder a rehacerlo según los originales que tengo» (Sanoja, 1998: 360). La respuesta parece que fue que debía hacer fuertes correcciones por lo que se deduce de otra de sus cartas: «¿qué rehaga El Motor? Bueno; mándamelo si es posible con Henrique si no por correo» (Sanoja, 1998: 363 y 370). El 12 de diciembre de 1911, vuelve a pedirle que le regrese este texto, «hazme el favor de mandarme Listos y Motor. Yo voy a consagrar mi vida a componer lo hecho» (Sanoja, 1998: 372).

Aún con fecha 5 de septiembre de 1912, le continuaba exigiendo la devolución del texto: «no dejes de mandármelo, cuanto antes, pues los primitivos originales se me han traspapelado i para refrescar la idea necesito releerla» (Sanoja, 1998: 377). Esta pieza, que fue publicada en 1959, sin embargo viene con fecha de escritura de 1910, y fue estrenada por la Compañía Nacional de Teatro de Venezuela el 10 de mayo de 1995. En este sentido, esta investigación estima, por lo visto anteriormente, que esta obra habría terminado de ser corregida a finales de 1912, como lo ha señalado también Juan Liscano (citado por José Santos Urriola, 1979: 327), aunque debe constar que Carlos Salas (1967) cuenta que el 28 de julio de 1910, El motor (junto a $L a$ selva de Soublette) le fue presentada a la Compañía española Fuentes-Arévalo para su estreno, y que Fuentes rechazó a ambas porque «requerían actores nacionales ... además de otros motivos ajenos a la empresa artística, que no quería inmiscuirse en asuntos políticos...» (p. 108).

De esta revisión surge también la noticia de una nueva obra, Listos, que ya le había enviado para su lectura a González en 1911, de la cual nada más se sabe hasta ahora. A partir de 1912 la correspondencia de Gallegos comienza a mencionar su siguiente obra, El milagro del año, ocasión en que le consulta a su amigo González: «si se publica el 'Milagro' me mandará 'Mundial'?» (Sanoja, 1998: 378). Luego, el 21 de enero de 1913, nuevamente se tienen buenas noticias sobre esta obra: «agradézcote tus elogios a propósito de «El milagro», inclusive lo de ser yo clásico» (Sanoja, 1998: 379). La pieza, que toma su tema al parecer de uno de sus cuentos del mismo nombre, se estrena en el Teatro Caracas, en noviembre de 1915 (repuesta en 1969), y fue publicada en 1959 junto a El motor (Villasana, 1969/79, vol. 3: 282).

Otras obras dramáticas que se mencionan de Gallegos son La esperada, escrita en 1915, con cuya trama escribió posteriormente su novela Canta- 
claro (1934), drama desaparecido (Subero, 1984: 8); La doncella, escrita en 1945 y editada en México en 1957, libro que obtiene el Premio Nacional de Literatura en 1958; Doña Bárbara, cuyo texto se encuentra extraviado, aunque fue estrenada en el Teatro Municipal en 1945 y cuya ópera, con guión de Isaac Chocrón, tuvo su preestreno en el Teatro Juárez de Barquisimeto, en 1967; y Las madamas, que menciona Raúl Díaz y de la que nada se sabe (Díaz,1975: 404).

Al revisar su actividad en el cine, ya se reconoce en Gallegos una nueva época, la de los años cuarenta, cuando en 1941 se convierte en productor y guionista de cine en su propia empresa Ávila Films y escribe una serie de guiones que deben sumarse a su creación dramática. Entre ellos se encuentran: Juan de la calle (1941), escrito especialmente para el cine, Doña Bárbara (1943), La trepadora (1944), La señora de enfrente (1945), Cantaclaro (1945), La doncella de piedra (1945?) y Canaima (1945). También se incluye la ya mencionada La doncella (escrita en 1945 y publicada en 1957, en México), efectuada por encargo de un productor cinematográfico mexicano y, en realidad, escrita como un guión de cine, pero con relevantes características dramáticas, no llevada al cine (Izaguirre, 1986).

Entre su consagración como novelista con Doña Bárbara, en 1929, y sus primeros dramas, median casi veinte años. En estas casi dos décadas, sólo en el primer decenio escribió teatro. Es pertinente hacer esta observación porque, sin duda, las grandes ideas y valores que surgirían en su novelística, a partir de los años treinta, como lo ha reconocido la crítica, fueron sembrados en estos primeros años en los cuales el teatro ocupó una posición central. Es más, aún dentro de este período inicial se escribirá una novela señera, como lo fue El último solar, publicada en 1920 pero escrita en 1913, en la que, incluso, incluyó algunos cuentos escritos hasta entonces (como Alma aborigen y La encrucijada, por ejemplo) como capítulos de esta primera novela (Subero, 1984: 8).

La novela El último solar es considerada una obra madura, como expresa Domingo Miliani (1985): «de recuentos generacionales, útil para estudiar lo ideales éticos, políticos y literarios de su grupo... punto de arranque al propósito de escribir el gran mural novelado de Venezuela» (p. 85), en donde se anuncian mitos cívicos como el mesianismo, los héroes simbólicos, y en la cual se hace referencia directa a los trágicos ecos de la llamada «Revolución libertadora» y de los movimientos guerrilleros subsiguientes (Manuel Antonio Rodríguez, 1975: 412) que merodean algunos de sus dramas. Pero, tal vez, lo más importante que puede aportar esta novela es que, aparte de dar una visión amplia y concreta de los miembros de su grupo - de hecho se 
identifican con claridad a algunos personajes como Reinaldo Solar con Soublette y al estudiante de ingeniería cuya tesis sería la construcción de un puente que abandona para escribir un drama quien no sería otro que su amigo González-, también entrega una completa lista de referencias culturales del nivel de formación literaria y dramática que éstos poseían.

En su lectura aparecen mencionados, entre otros, autores como Tolstoy, Zola, Nietsche, Byron, Maeterlink, Emerson, Visen, los maestros del Realismo y del Modernismo. Será interesante ilustrar esta opinión con una muestra de esta novela, como expresa Reinaldo al regresar del interior del país y que recordará una de las obras ya revisadas en páginas atrás de Soublette:

ifastidio, embrutecimiento, hambre, paludismo! El espíritu vuelto un guiñapo; el cuerpo un hervidero de parásitos y de bacterias. Hube de abandonar al fin mi violín, mi buen hermano de infortunios; dejé de escribir mis dramas y así me quedé sin emociones estéticas. $Y$ venga el horrible y cotidiano temblor del paludismo. Al fin, un amigo que me depara el azar: Guaicaipuro Peña. Un ganadero rico y estólido, no sé si más rico que bruto o más bruto que rico. ¡Pero bueno, eso sí! Advierte que me estoy muriendo, y en un viaje que hace me trae entre su vacada como un maute más (Gallegos, s/f: 37).

Respecto a su obra Los ídolos, en cuatro actos, ésta ocurre en un asilo de mujeres muy bien demarcada en sus aspectos escenográficos, así el Dr. Lizardo es un «sugeto enfático que viste de negro i lleva lentes oro». La intriga es develada desde el inicio, como lo señala la discusión del Padre Terencio y el Dr. Lizardo:

P. Terencio: Amigo, hai que ser prácticos; el fin justifica los medios, i después de todo, quieras que no, este es el asilo de la Magdalena i está sometido a las disposiciones de la autoridad eclesiástica, según consta en sus reglamentos, que no podemos decir que no se cumplan.

Lizardo: No se haga ilusiones, Padre Terencio; aquí quien manda es Casalta. Ni el señor Obispo, ni Ud., ni mi esposa como Presidenta de la Junta fundadora, ni yo como su representante, tenemos pizca de autoridad ni verdadera ingerencia en el Instituto. I la prueba es palpable: esto que fue fundado única y exclusivamente para proteger á mujeres pobres pero de reconocida honradez, es hoy, $i$ «quieras que no», un refugio de... meretrices, más o menos arrepentidas (Gallegos, 1912/1920?: 3).

Como suele ocurrir en este tipo de instituciones, siempre hay alguien que se aprovecha de los otros, en este caso el Dr. Lizardo que maneja el albergue en el que se ha ido enriqueciendo con las aportes de señoras donadoras, 
que han creído en un plan de caridad que incluso tiene alcance mayor, pues él le ha propuesto al gobierno construir una red de estos asilos que él mismo dirigiría. Todo se encuentra planteado en un libro que ha escrito Casalta, en el cual pone como medio indispensable para la beneficencia y recibir beneficios religiosos a la ciencia médica y esto ha convencido a todos:

Amaral: ...Si yo mismo a duras penas resisto. Pobre hijo mío sentenciado a muerte por la superstición i la ciencia!

Casalta: Qué quieres decir con eso?

Amaral: Sabe Ud. cuál fue una de las causas que más influyó para que Eulalia tomara que aquella determinación? Su libro.

Casalta: Mi libro?

Amaral: Sí, la Ciencia; el fracaso de la ciencia!

Casalta: Qué has dicho?

Amaral: Éste es uno de mis ídolos caídos. Como tengo el alma lleno de escombros! Los escombros de todos mis ídolos! ...Cuando Ud. me mandó aquel libro lo vi como á una puerta de esperanza que se abría. Todos los días le leía trozos de él a Eulalia, explicándoselos, sobre todo aquel capítulo donde Ud. propone los métodos de selección social. Cuánta ciencia! Quien iba a decirme que todo aquello sería el golpe de gracia asestado sobre la única esperanza de Eulalia: su hijo? Según aquel libro nuestro hijo... (Gallegos, 1912/1920?: 59).

Las cosas se enredan más aún porque el hijo de Amaral, siempre enfermo, muere. Este hombre, que tiene una profunda fe religiosa, se enfrenta ahora en el cuarto acto a la separación de su esposa. Le pide que sacrifique su alma en un momento clímax y final de la obra:

Amaral: Sí; una última puerta se abre hacia una blancura infinita, más allá del dolor: la muerte! El último ídolo! Todos han ido cayendo sobre nuestras almas, destrozados! Primero fue mi Dios; luego mi obra; tu amor, nuestro hijo después! Hagamos ahora nuestro último ídolo con los escombros de todos los que cayeron! Aún queda una esperanza para nosotros: morir! Qué delicioso es morir después que se han conocido todos los dolores! ...Hemos sufrido tanto! Hemos llorado tantas ilusiones muertas! ...Ya no queda en la vida un dolor, ni una lágrima en nosotros! ...Ahora: el fin, la destrucción, la suprema paz helada i blanca!... (Gallegos, 1912/1920?: 79).

Se ha señalado, no sin razón, que existe cierta relación o similitud entre esta pieza y Los predestinados (1909, publicada en 1984). En efecto, perso- 
najes como Casalta, Eulalia, Claudio Amaral y Sor Berenice son los mismos en ambas obras, en las que se percibe el sino de una tragedia, permanece una retórica simbolista desde su título y la dualidad razón-religión, aunque esta última tiene cinco actos y no cuatro como en Los ídolos y el final difiere sustancialmente entre ambas. En este sentido, Orlando Rodríguez (1993) señala que el autor reelaboró la obra cambiándole el título a Los predestinados, definiéndola como «tragedia interna en un acto, precedida de un prólogo en cuatro etapas» y en la cual un sacerdote sería el protagonista, lo que es diferente en Los ídolos, en donde el Padre Terencio no tiene un rol tan protagónico (O. Rodríguez, 1993: 6; O. Rodríguez, 1988, vol. 4: 239 y Monasterios, 1986: 284-285).

Recientes estudios al respecto, como el de Yelitza Ramírez (2004), al indagar en forma comparativa en ambas obras sobre sus valores, ideología y señales discursivas, desde la dimensión del discurso teatral, concluye que Los ídolos y Los predestinados tienen ambas 4 actos, aunque en la primera cada acto se divide en múltiples escenas, entre 11 y 23, en cambio en la segunda son sólo actos con escena única, la primera es un poco más extensa (24.950 palabras contra 24.152) y con mayor número de parlamentos que la segunda(1578 contra 1533); en ambas el tiempo avanza progresivamente, lo cual les permite «crear un efecto de realidad»; ambas se desarrollan en un hospicio regido por el Dr. Casalta en colaboración de Las Hermanas de la Caridad, a la espera de Claudio Amaral, sacerdote desertor de su ministerio, quien en el acto III aparece y se da el salto hacia el futuro; el único personaje jovial y de mentalidad liberal es Isabel, quien sólo aparece en Los ídolos y cuyos turnos se atribuyen en Los predestinados a Eulalia, a quien correspondería al reverso de la medalla.

Eulalia, en este sentido, es presentada como otra insana más, dándole más dramatismo a esta obra, mientras que su correspondiente en la otra obra es una huérfana a cargo de las monjas que culmina tomando los hábitos. El fin «en Los ídolos es la búsqueda de la propia muerte como el último ídolo y en Los Predestinados es la vuelta de Eulalia al hospicio y de Amaral al exterior. Tal y como empezó» (Ramírez, 2004: 5).

Respecto a la obra La doncella, señalaré que fue escrita en México durante su exilio y publicada en 1957 en un libro que, junto al drama, incluye nueve cuentos escritos en la primera década del siglo XX (denominado El último patriota). La pieza aparentemente fue escrita bajo la forma de guión para un realizador mexicano, en 1945, que nunca fue llevado a la pantalla. Consta de treinta y siete escenas, en las cuales el tema central es la vida de la 
legendaria Juana de Arco, siguiendo una cronología histórica, y que tiene un ritmo ágil, pleno de poesía, con ambientes precisos del medioevo (O. Rodríguez, 1993).

La obra, El milagro del año, fue estrenada en 1915, reestrenada en 1969, versionada para la televisión y publicada en 1959. Su fábula fue tomada de uno de sus cuentos homónimos. Definida por su autor como tragedia en tres actos, transcurre en una aldea isleña de pescadores, perleros y contrabandistas, cuyos protagonistas son Valentín, alias el chavalo, hermano del Padre Juan, en cuya casa se realizan las escenas, Toñita y otras personas del pueblo. Se rumora que Valentín, quien ha sobrevivido a dos naufragios, ha hundido la goleta para robar el dinero que llevaba. Él, además, es el pretendiente de Antonia, quien lo rechaza por saber que efectivamente cometió el delito, pero esto mismo hace que Valentín la amenace de muerte si revela el secreto. En el segundo acto, estas líneas argumentales comienzan a mostrar los efectos supersticiosos y de maleficios que se enfrentan:

Valentín: Mujer, ¿Quién ha mentao culpa? (Pausa) Mira. Mira el milagro que le había prometío a la Virgen. A ve qué te parece. En la mano derecha se lo voy a colgá con esta cinta. Sopésalo. Es de plata maciza.

Antonia: Ya lo veo desde aquí.

Valentín: $Y$ mira. (Saca una pulsera). Esto es pa ti. Unas pulseras pa que te las pongas mañana en la fiesta.jVas a está más bizarra! Atócalas mujer. A ve, que te las voy a poné yo mismo.

Antonia: Puedes botarlas. Que primero me vea muerta que favorecida por nada tuyo.

Valentín: Ya yo estaba aguardando eso, desagradecía. Maldita sea la hora y punto en que te cogí este capricho.

Antonia: ¿Quién te manda a tenerlo todavía? Y no me maldigas tanto, que se pueden trocar las sentencias (Gallegos, 1959: 1.332).

Finalmente, en el tercer acto, durante la procesión de la Virgen, el Padre Juan efectúa un sermón angustioso y dice que el criminal «está entre nosotros», y le pide a la Virgen del Mar que haga el milagro de descubrirlo, el cual sería el milagro del año. El pueblo se enardece y hacen justicia por sus manos. Al morir Valentín desaparece el maleficio de Antonia.

La pieza mantiene una tensión permanente, en donde queda claro el ambiente de tragedia que rodea a Valentín, muy al estilo de O`Neill, es decir, casi un héroe y cuya acción está dirigida en forma directa a su culminación 
trágica, rodeada de creencias, maleficios y mitos. Valentín le había pedido a la Virgen como gracia un dinero para comprarse un barco, por lo que en su mentalidad ésta era una especie de cómplice suyo y él un pecador influido por la fe.

La participación del pueblo adquiere el aspecto de coros, que, a través de voces, van pidiendo justicia: «jel milagro..., el milagro..., el milagro!» (1.358), lo cual no deja de ser una novedad para el teatro de la época. Esto no sólo muestra un conocimiento del alma del pueblo, de sus mapas mentales, sino que también significa que Gallegos logra penetrar en la mente de sus personajes y del pueblo. Para Monasterios (1986) la pieza, y especialmente su última escena, es «un soberbio ejemplo de ese gran melodrama naturalista» (p. 294); para Rodríguez (1988 y1993) el comportamiento del pueblo recuerda a Fuenteovejuna de Lope de Vega, debido a que la pieza «posee elementos que la hacen acercarse a la tragedia» (pp. 239, y 6 respectivamente). Es interesante destacar que en esta obra es muy evidente el uso, por parte de Gallegos, de lo que posteriormente se denominaría «realismo mágico», aspecto que se comentará en mayor extensión más adelante.

Tal vez, la obra más conocida, estudiada y sujeta a crítica sea El motor, por lo demás también, la más difundida. Escrita en Caracas, en julio de 1910, dedicada a sus compañeros de La Alborada, lleva igualmente una dedicatoria adicional del autor que puede resultar clave para entender sus ideas respecto de la pieza: «y a todos cuantos estén: en presencia de un espacio capaz para encerrar vuelos infinitos, inmóviles, extendidas las alas de un altivo sueño glorioso en la espera del impulso que los haga remontar» (Gallegos, 1959: 1.215).

La fábula de esta pieza, definida como drama en tres actos, se relaciona con los sueños de Guillermo, un joven culto, poeta, maestro del pueblo Pegujal, quien nunca ha salido de allí, y que inspirado en las lecturas de Leonardo se ha empeñado en construir un avión para salir fuera. Guillermo Orosía, según se deduce, tomado de la figura de su amigo Salustio González (que hastiado de ambiente nacional se fue en busca de nuevos horizontes, como ya se ha visto en páginas atrás), de origen humilde, viste traje blanco y lleva siempre una rosa en el boutonnier, lo cual formaría parte de su forma de oponerse al sistema a ese medio campesino y diferenciarse de un contexto que, en términos galleguianos, sería bárbaro. Por otra parte, es un frustrado que se siente incomprendido y se encuentra obsesionado por la idea de construir ese avión que ya, en su segunda versión, como lo explica en el tercer acto: «iel motor!... ¡lo que hace falta es el motor!... Se tiene alas, pero con 
alas sólo no se vuela..., es necesario el motor: el impulso. ¡De aquí no puede partir el impulso, pero en otros lugares existe y en ellos se puede volar, subir, subir muy alto!...» (1.290).

La otra línea argumental, secundaria en la pieza, y que se conecta a la idea del avión, es la anunciada visita del General-presidente que observará la prueba de fuego del avión y el consiguiente templete que espera el pueblo, lo que ocurre al final del segundo acto. Los diferentes personajes van relatando cómo sacan el aparato, cuando Guillermo sube al avión, no hay viento, aparece viento, rueda el avión y «parecía que iba a subir, pero se paró de frente» (1.276). También en esta línea se puede incluir la presencia de otro invento moderno, el cine, cuando Mister Gilby, un norteamericano, proyecta en un acto al aire libre, una película para el general. Guillermo pierde su puesto en la escuela y deberá irse, la única forma de recuperar esa posición sería leyéndole un discurso al presidente y él no está dispuesto a hacerlo "iqué mal dotado están ustedes para vivir aquí!» (1.297).

Lo más interesante, para el estudio de esta obra, es que esta investigación pudo contar con el informe de su puesta en escena por parte de su director Javier Vidal (1995), especie de libro de montaje, en donde se estudian muchos de los aspectos que presenta la pieza a la hora de llevarla a escena. De partida, la obra fue considerada un teatro de ideas, «la primera referencia latinoamericana de un teatro de ideas. Unas ideas que se expresan de una manera lúcida dentro del positivismo que emerge frente al hombre nuevo de la Venezuela de principios de siglo» (19). En este mismo sentido, el director indica que «lo nacional $v s$. lo universal es quizá la piedra angular del tema de El motor» (20), y se «centra la acción en un realista y a la vez mágico pueblo de nombre Pegujal» (20). Igualmente, por las pocas referencias que señala la obra sobre quién es el General-presidente, como que es un «frívolo que no está a tiempo en las citas de protocolo porque aún se está cambiando ropa, nos inclina a suponer que el retrato hablado en el drama de Gallegos se trata de Cipriano Castro» (22); a diferencia de lo que señala con reiteración Rodríguez que se trataría de Gómez (1983: 239 y 1993: 5), que más bien sigue la opinión de Monasterios (1986: 286), y de la autorizada voz de Manuel A. Rodríguez (1975: 412).

Desde otro punto de vista, el director coincide con Orlando Rodríguez y Monasterios en que el lenguaje es en parte retórico, expositivo, aunque «las pausas, transiciones, planteamientos de la crisis, clímax y desenlace, muestran una estructura y coherencia, difícil de encontrar en las obras venezolanas de esos años» (23). 
Para la puesta en escena, Vidal hizo una nueva versión de la obra, «obligada lectura alternativa», que no traiciona las ideas del autor: «me interesaba presentar en el contexto actual, la visión de un país y de un héroe que finalizando el siglo aún sueña con volar a sabiendas que el vuelo fracasará» (58). En esta versión se hicieron algunos arreglos a la ideas del texto y en la cual se dio importancia a:

la producción de imágenes visuales en escena... De esta manera aparecerá en escena el vuelo del protagonista como prólogo de una escena que se describe en el drama (en el segundo acto)... La escena del baile que también se cuenta con detalles y en la puesta en escena se escenifica. El fracasado vuelo con los avanzados medios del video y la escenificación, también, del cinematógrafo, que en Gallegos simplemente se narra sin aparecer imágenes, ni el aparatoso invento de los hermanos Lumiere. [...] Por otra parte, los tres actos quedan compactados en un solo acto con prólogo (el vuelo de Guillermo Orosía) e interludio (El vals del General: 58).

En cuanto a la significación de la obra, en principio, las referencias al motor y al cine son elementos relevantes de la vanguardia futurista sin duda, que ya era conocida en Venezuela. Igualmente, es evidente la necesidad que tuvo Gallegos por mostrar la realidad cultural y política en que le tocó vivir, con su carga de fracaso, de evasión, de desesperanza, ante una realidad brutal, lo que muestra una significativa conciencia histórica del autor. Igualmente es la presentación de personajes nuevos para el teatro, como la del intelectual pueblerino, la del arribista servidor de su jefe, y la de la madre tierna, fiel a su familia como la tierra.

La obra, sin embargo, y a pesar de lo ya observado, fue vista por Monasterios, primero, como que «no pasa de ser una pieza más el pedestre Teatro Criollo venezolano» (1968, p. 21); luego, «de un melodrama burgués (con acento emocional dramático, o dramático humorístico) para una rama del teatro criollo» (1986: 286) y «que encuadra fácilmente en el Teatro Criollo; nada verdaderamente singular, en realidad, pero la lectura de esta pieza, escrita con evidente intención didáctica —uno de los grandes pecados del teatro Criollo-» (1990: 38). A su vez, Orlando Rodríguez (1988) la califica como «comedia dramática», aunque le reconoce una visión ibseniana del mundo ya conocida en el continente (238). Todos calificativos relevantes y definidores de una obra compleja.

De sus guiones para el cine, la mayor parte escritos con el fin de pasar sus novelas a este medio, como ya se vio, uno de ellos lo escribió especialmente para el cine, cual fue Juan de la calle, escrito en 1941 y que no deja 
de resumir sus experiencias dramáticas de hacía treinta años. Este guión marcó un hito en el cine nacional porque fue escrito especialmente por un escritor profesional de la estatura de Gallegos. La película narra la historia de Juan, la vida de un muchacho de la calle que abandona a su madre, que vive en un ambiente de concubinato. En su huida ejerce variados oficios hasta que un día conoce a una bella muchacha de la cual se enamora y siente que es el momento de rehacer su vida. Mas pronto se entera de que la muchacha se ha mudado, que alguien se la ha llevado con el fin de explotarla sexualmente. Juan reacciona incendiando la casa de esta Celestina y vuelve a sus andanzas iniciales como pandillero en busca de su libertad, hasta que un día se encuentra con un viejo, vagabundo también, que es filósofo, suerte de símbolo de reformación, quien convence a Juan para que ingrese en un reformatorio o retén para menores que acaba de inaugurarse, bajo el amparo del Estado, en donde parece asentarse en definitiva (Izaguirre, 1986: 304).

Los negativos de esta película, al parecer, se perdieron en el incendio de los estudios de su propiedad, Ávila films. La Cinemateca Nacional logró recuperar una copia de trabajo que es la que dispuso esta investigación para verificar los perfiles de sus principales personajes como Margarito, el corruptor de menores; la cabrona; Don Timoteo, el personaje cómico; Morisquetas, el amigo de Juan y su lema «mitad y mitad, en lo bueno y en lo malo, a juro!»; y confirmar en su actual estado, con defectos de audio de origen, su factura realista y de alto contenido social que se adelanta a su tiempo.

En opinión de Izaguirre, la película trataba de apoyar un proyecto del Ministerio de Educación que deseaba crear una red de centros o Casas de Observación para Maestros o Retenes con el fin de atender a menores marginales o delincuentes (recuérdese Los ídolos y los personajes marginales de sus obras), insistiendo siempre en su constante de la necesidad de educación, lo que debilita la trama (Izaguirre, 1986: 304).

La crítica, sin embargo, fue elogiosa, aunque no se recuerda como un éxito resonante, tampoco de fracaso. Junto a la coherencia de su argumento y realización se le objeta un desarrollo melodramático y que el final resultaba como falso y moralista. Estrenada el 27 de noviembre de 1941, en los teatros Principal y Caracas, representó la mejor película filmada en el bienio 19411942; luego se presentó en la provincia y años más tarde se perdieron sus originales y ya no se volvió a saber de la película. Con Juan de la calle terminó también Ávila films y la experiencia de Gallegos en el país (Izaguirre, 1986: 305). Luego, esta historia continuará en México, en donde en un ambiente 
más estimulante y con una industria cinematográfica más desarrollada se hicieron cinco películas de su autoría, gran legado documental de su obra.

\section{PALABRAS FINALES}

La presencia de Gallegos en el teatro no sólo abarca sus propios dramas, sino que también se han llevado a escena muchos sus cuentos, como, por ejemplo, El pasajero del último vagón, que pusiera en escena con éxito el Grupo Rajatabla, en 1984. Esto muestra que la obra cuentística de Gallegos, contemporánea a su teatro, no sólo posee una significativa teatralidad, sino que también pone en evidencia la vigencia de su temática, lo cual no debería dejarse de observar.

Igualmente, se podría señalar que la crítica de su teatro no siempre comprendió sus propuestas dramáticas en toda la magnitud deseable; prueba de ello sería que en los años setenta, cuando ésta comienza a revisarse, surge una valoración diferente, como es el caso de Rafael Varela, quien al comentar sobre este aspecto la obra El milagro del año, en 1979, ha expresado que es una «obra amarga y dura que apenas obtuvo mención de la crítica y que es tal vez el mejor ensayo que en su género se ha hecho en Venezuela» (p. 43), o las expresiones de Barrios (1997) cuando hace el reconocimiento a que «la provincia entra en etapa de franco deterioro, desolación que reflejarán sobresalientes piezas dramáticas como El motor (1910), de Rómulo Gallegos y, más tarde, Mala siembra (1949), de Luis Peraza, Macaurel (1943), de Aristyde Calcaño y El pueblo (1942), de Víctor Manuel Rivas» (p. 31), además de considerarla una pieza clave de la época (p. 51), con lo cual queda en claro también la proyección de su obra.

Una visión más amplia de su obra no puede desligarse, no obstante, de los principios generales modernos que esbozaran los alborados en aquellos mismos años, vale decir, el tratar de explicar e interpretar lo específico de la realidad que observaban en su país, especialmente su subdesarrollo, por ello junto con aludir al experimentalismo, no desdeña lo novedoso y lo creativo, tratando de entregar una esencia cultural de Venezuela (e, incluso, de Latinoamérica), como también lo apuntara Azparren (2002). Este enfoque se dirige especialmente a detectar las fallas del sistema educativo, cuestionar la herencia cultural hispana (autocomplacencia, emocionalismo, individualismo en exceso), oponerse a una dinámica política violenta para establecer una conciencia cívica, poner fin a la dictadura y a la corrupción, y con esto lograr 
un deseado progreso. Su búsqueda de nuevos valores indica que éstos sólo se podrían lograr mejorando al ser humano.

Según Monaterios (1983), su obra dramática antecedería y sentaría las bases para esta temática en el boom de la novela latinoamericana, porque el campo latinoamericano es una realidad determinante y una riquísima fuente de creación para lo que se ha denominado el realismo mágico. Lo mismo podría decirse de la telenovela venezolana que toma una dimensión trágica muy galleguiana, variante de la griega clásica, adaptada al país en aspectos de las relaciones casta/sangre y la relación de sus personajes con el ambiente. Monasterios (1986) también se refiere a esto al expresar que el autor acentúa el tema del aislamiento del rezago cultural de los pueblos latinoamericanos y de la distancia que los separa del desarrollo, dándose una «correspondencia entre tal planteamiento y uno de los múltiples asuntos de esa gran fábula de nuestro tiempo: Cien años de soledad, de García Márquez, uno de cuyos insólitos personajes también inventa por su cuenta el hielo» (289), en alusión al invento del avión en la obra El motor.

Todas estas interpretaciones probablemente encontrarían una acertada respuesta en el mismo Gallegos si se le consultara, en el contexto de aquellos años, cómo entendía la arte. Su respuesta, al calor de su escritura dramática, en 1911-1913, fue la siguiente:

yo creo que el arte que perdura no es el que sólo tiene verdad, sino el que además tiene, por una parte: personalidad; es decir: que sea la expresión de la manera propia de sentir el artista, el cual tiene tanto derecho a ser tenido en cuenta como la naturaleza, ó sea el mundo de las realidades o apariencias, que dije más atrás; i por otra parte: trascendencia, alcance, profundidad, raíces ó como quiera llamarse a esto que, a mi manera de entender, no es sino armonía perfección i que para mi consisten en tener tanto de emoción como de intelectualidad (Celarg, 1998: 370).

[...] Ésta es mi teoría: ser espontáneos, hasta en la imitación. Creo que si algo he de ser en literatura, no será por escribir como dicen que debe escribirse ahora, sino por poner en mis obras mi manera de ser; manera que no se limita a los conceptos y a los sentimientos, sino que comprenden también el estilo (Celarg, 1998: 379).

Con todas estas ideas, contenidos y significados de sus obras dramáticas, muchos se preguntarán por qué Gallegos dejó de escribir teatro. La respuesta, nuevamente, podría encontrarse en la correspondencia con sus amigos alborados de aquellos años. En primer lugar, Gallegos no parecía incli- 
nado a publicar sus obras, como le señala a González en diciembre de 1911: «yo me pasaría la vida escribiendo i componiendo i no publicaría nunca. Cuando uno publica algo, pierde el derecho de propiedad sobre sus ideas» (Celarg, 1998: 372). En segundo lugar, tenía temores de que sus dramas no estuvieran bien escritos, por eso siempre los daba a leer a sus amigos y volvía a corregirlos, una y otra vez, como le decía en la misma carta a su amigo: «mándame pues mis dramones para ponerme a componerlos, a ver si de aquí á cuando me muera he logrado hacer un par de dramas perfectos, si mis herederos quieren publicarlos...» (Celarg, 1998: 372).

Finalmente, se podría señalar que en aquellos años la escritura para Gallegos suponía también la obtención de cierto reconocimiento que no imaginaba en el teatro, y, con una visible desazón, le comentaba al mismo González, en 1910:

[...] mientras tanto escribiendo de nuevo, cuentecitos para El Cojo, por lucro únicamente, como que los hago por sacarles unos pesos mensuales que necesito. Y me quedan que da gusto verlos, ¿así son de crecidos, dramas? Había jurado no escribirlos más. ¿Para qué? Para que me pase con ellos lo que Henrique con la S... [se refiere a la obra La selva de Henrique Soublette]. Por eso, repito, había jurado no perder más mi tiempo escribiendo dramas. Ahora dices tú, que puede ser, que quizás, que quien quita. ¡Ojalá! (Celarg, 1998: 357).

Gallegos y, en general, todos sus amigos dramaturgos de La Alborada vieron en el realismo el estilo por medio del cual satisfacer sus anhelos éticos, políticos y dramáticos que comportaba el grupo e inician, sin duda, una etapa que se aleja del criollismo, cercana a una preocupación social y estética con fuerte acento civilista y educativo, que exploró nuevas dimensiones dramáticas para el país, breve preámbulo de un modernización del teatro venezolano que por estas sendas buscaría en el tiempo su renovación.

\section{REFERENCIAS BIBLIOGRÁFICAS}

ALCIBIADES, Mirla (1989). «Presencia y permanencia de El Cojo Ilustrado». Suplemento Cultural de Últimas Noticias, 26 de febrero, 10-11.

- (1995). «El Cojo Ilustrado» en el proceso de la modernidad en Venezuela. Trabajo de Grado. Maestría en Literatura Latinoamericana. Caracas, Universidad Simón Bolívar. Inédito. 
AZPARREN, Leonardo (2002). «El primer discurso teatral moderno en Venezuela: la dramaturgia de La Alborada». Revista Extramuros 16, 97122.

BARRIOS, Alba Lía; MANNARINIO, C. e IZAGUIRRE, E. (1997). Dramaturgia venezolana de siglo XX. Caracas: Ediciones ITI-UNESCO.

BILBAO, Alicia (1989). «El discurso amoroso en la narrativa venezolana de la modernización». Suplemento Cultural de Últimas Noticias, 26 de febrero, 4-5.

CARRERA, Liduvina (2001). «La estética modernista en la dramaturgia de El Cojo Ilustrado». Boletín Universitario de Letras (CIILL, UCAB) 6, 105-139.

CELARG (1998). Salustio González y la generación de «La Alborada». Caracas: CELARG. Biblioteca de Autores Tachirenses.

COSMÓPOLIS (1894). Caracas, $1 .^{\circ}$ de Mayo.

DÍAZ, Raúl (1975). «Rómulo Gallegos. Bio-bibliografía». Revista Araisa (Anuario del CELARG), 393-406.

GALLEGOS, Rómulo (s/f). Reinaldo Solar. Lima: 3. ${ }^{\text {er }}$ Festival del Libro Venezolano.

- (1919/192?). Los ídolos. Manuscrito fotocopiado del autor.

— (1959). El milagro del año. Madrid: Edime (1.215-1.300).

— (1959). El motor. Madrid: Madrid: Edime (1.301-1.363).

- (1984). Doña Bárbara y Los predestinados. Caracas: Ed. Papi.

GRASES, Pedro (1944). En el cincuentenario de Cosmópolis. Selección de artículos doctrinales. Caracas: Ediciones del Instituto Pedagógico Nacional.

- (2001). Entrevista personal en Caracas, con fecha 30 de septiembre, 1999.

IZAGUIRRE, Rodolfo (1986). «Gallegos y el cine». En Rómulo Gallegos, Multivisión, Isaac Pardo y Óscar Sambrano U. (coords.), 304-305. Caracas: Ediciones de la Presidencia de la República.

LAZARTE, Javier (1994). «El teatro de Rómulo Gallegos». Entrevista de José A. Rial en el Programa de TV, Canal 8, El teatro y sus máscaras. Copia en vídeo del autor. 
LA PROCLAMA (1910). Semanario de combate. En CELARG (1998), Salustio González y la generación de «La Alborada», 441-443. Caracas: CELARG. Biblioteca de Autores Tachirenses.

MEDINA, José R. (1963). «Prólogo». En Cuatro novelas cortas, J. Rosales, IX-LXI.

MILIANI, Domingo (1985). Tríptico cultural venezolano. Caracas: Fundación de Promoción Cultural de Venezuela.

MONASTERIOS, Rubén (1968). «Las dos posibilidades del dramaturgo». Revista Imagen 32, 7.

- (1983). Un enfoque crítico del teatro venezolano. Caracas: Monte Ávila.

- (1986). Rómulo Gallegos, dramaturgo. Caracas: Monte Ávila.

OSORIO, Nelson (1988). Manifiestos, proclamas y polémicas de la Vanguardia literaria hispanoamericana. Caracas: Biblioteca Ayacucho.

PARDO, Isaac y Óscar SAMBRANO U. (coords.) (1986). Rómulo Gallegos, Multivisión. Caracas: Ediciones de la Presidencia de la República.

PLANCHART, Julio (1944). «Jesús Semprúm». Revista Nacional de Cultura 23 (Nota n. ${ }^{\circ}$ 17).

- (1972). Temas críticos. Caracas: Ediciones de la Presidencia de la República.

RAMÍREZ, Yelitza (2004). Caracterización de las estrategias retórico-argumentativas en «Los ídolos» y «Los predestinados» (1910-1912?). Trabajo para la Cátedra Discurso e ideología en la Maestría en Estudios del discurso, UCV, FHE. Inédito.

RODRÍGUEZ, Manuel Alfredo (1975). «Rómulo Gallegos en Guayana». Revista Araisa (Anuario del CELARG), 407-415.

RODRÍGUEZ, B. Orlando (1988). «1900-1945: Una herencia largamente prolongada». Escenario de dos mundos 4, 234-249.

— (1993). «Rómulo Gallegos y la dramaturgia». Revista Theatrón 2, 5-8.

SALAS, Carlos (1967). Historia del teatro en Caracas. Caracas: Ediciones de la Gobernación del Distrito Federal.

SANOJA, Jesús (1998). «Salustio y su tiempo entre las sombras». En CELARG, Salustio González y la generación de «La Alborada», 3-24. 
SUBERO, Efraín (1984). «El maestro Gallegos». Revista Nosotros (Lagoven). Caracas, julio. Edición especial dedicada al 1. ${ }^{\text {er }}$ Centenario del nacimiento de Rómulo Gallegos.

URRIOLA, José Santos (1979). «La primera versión de El forastero: novela inédita de Rómulo Gallegos». En CELARG, Relectura de Rómulo Gallegos. XIX Congreso Internacional de Literatura Iberoamericana. Caracas: Celarg.

VIDAL, Javier (1995). Informe de la versión y dirección de «El motor» de R. Gallegos, realizado para la Compañía Nacional de Teatro. Maestría de Teatro Latinoamericano, Universidad Central de Venezuela. Inédito.

VILLASANA, Ángel Raúl (1969/79). Repertorio bibliográfico venezolano (1808-1950). Caracas: Instituto Autónomo Biblioteca Nacional-FUNRES, 6 volúmenes. 